\title{
Right ventricular failure secondary to chronic overload in congenital heart disease: An experimental model for therapeutic innovation
}

\author{
Virginie Lambert, $\mathrm{MD}, \mathrm{PhD},{ }^{\mathrm{a}, \mathrm{b}, \mathrm{c}}$ André Capderou, $\mathrm{MD}, \mathrm{PhD},{ }^{\mathrm{a}, \mathrm{b}}$ Emmanuel Le Bret, $\mathrm{MD}, \mathrm{PhD},{ }^{\mathrm{c}}$ \\ Catherine Rücker-Martin, $\mathrm{PhD},{ }^{\mathrm{a}, \mathrm{b}}$ Edith Deroubaix, $\mathrm{PhD},{ }^{\mathrm{a}, \mathrm{b}}$ Elodie Gouadon, $\mathrm{PhD},{ }^{\mathrm{a}, \mathrm{b}}$ \\ Nicolas Raymond, BSc, ${ }^{\mathrm{a}, \mathrm{b}}$ Bertrand Stos, MD, ${ }^{\mathrm{c}}$ Alain Serraf, MD, PhD,,${ }^{\mathrm{b}, \mathrm{d}}$ and \\ Jean-François Renaud, $\mathrm{PhD}^{\mathrm{a}, \mathrm{b}}$
}

Objective: Mortality and morbidity related to right ventricular failure remain a problem for the long-term outcome of congenital heart diseases. Therapeutic innovation requires establishing an animal model reproducing right ventricular dysfunction secondary to chronic pressure-volume overload.

Methods: Right ventricular tract enlargement by transvalvular patch and pulmonary artery banding were created in 2-month-old piglets $(n=6)$ to mimic repaired tetralogy of Fallot. Age-matched piglets were used as controls $(n=5)$. Right ventricular function was evaluated at baseline and 3 and 4 months of follow-up by hemodynamic parameters and electrocardiography. Right ventricular tissue remodeling was characterized using cellular electrophysiologic and histologic analyses.

Results: Four months after surgery, right ventricular peak pressure increased to $75 \%$ of systemic pressure and pulmonary regurgitation significantly progressed, end-systolic and end-diastolic volumes significantly increased, and efficient ejection fraction significantly decreased compared with controls. At 3 months, the slope of the endsystolic pressure-volume relationship was significantly elevated compared with baseline and controls; a significant rightward shift of the slope, returning to the baseline value, was observed at 4 months, whereas stroke work progressed at each step and was significantly higher than in controls. Four months after surgery, QRS duration was significantly prolonged as action potential duration. Significant fibrosis and myocyte hypertrophy without myolysis and inflammation were observed in the operated group at 4 months.

Conclusion: Various aspects of early right ventricular remodeling were analyzed in this model. This model reproduced evolving right ventricular alterations secondary to chronic volumetric and barometric overload, as observed in repaired tetralogy of Fallot with usual sequelae, and can be used for therapeutic innovation. (J Thorac Cardiovasc Surg 2010;139:1197-204)

\section{Supplemental material is available online.}

Adult patients with congenital heart disease represent an increasing population as advances in surgery significantly improve the short-term prognosis. However, right-sided heart failure remains a major problem in the long-term

\footnotetext{
From the Département de Recherche Médicale, ${ }^{\mathrm{a}}$ CNRS UMR 8162, Centre Chirurgical Marie Lannelongue, Le Plessis Robinson, France; Université Paris Sud, ${ }^{\mathrm{b}}$ Orsay, France; Department of Pediatric Cardiology and Cardiac Surgery, ${ }^{\mathrm{c}}$ Centre Chirurgical Marie Lannelongue, Le Plessis Robinson, France; and Experimental Surgery Laboratory, ${ }^{\mathrm{d}}$ Centre Chirurgical Marie Lannelongue, Le Plessis Robinson, France.

Supported by the Association Française contre les Myopathies 12063 and 13056, Evry, France; and Agence Nationale pour la Recherche ANR-06-MRAR-041-03 Cardiostem, Paris, France.

Disclosures: None.

Received for publication June 19, 2009; revisions received Oct 7, 2009; accepted for publication Nov 14, 2009.

Address for reprints: Virginie Lambert, MD, Centre Chirurgical Marie Lannelongue, 133 Avenue de la Résistance, 92350 Le Plessis Robinson, France (E-mail: v.lambert@ccml.fr).

0022-5223/\$36.00

Copyright (c) 2010 by The American Association for Thoracic Surgery

doi:10.1016/j.jtcvs.2009.11.028
}

follow-up, leading to impairment of functional status, severe arrhythmia, and premature death. ${ }^{1,2}$ Current therapeutic options for these patients are limited and show temporary results. ${ }^{3}$ Moreover, studies evaluating the effects of usual drugs on the right ventricle ${ }^{4}$ provide the emergent idea that right ventricular (RV) adaptative pathways differ from those of the left ventricle. ${ }^{5}$ Investigations and development of new therapeutic approaches need to be pursued. To develop therapeutic strategies to protect the right ventricle against remodeling and prevent early morbidity and mortality, it is critical to create an animal model showing RV functional and structural remodeling as observed in congenital heart disease.

Among congenital heart diseases that result in long-term RV failure, repaired tetralogy of Fallot (TOF) is one of the most frequent. After a successful repair, favorable outcome is normal, but the long-term course may be impaired by severe ventricular arrhythmia and RV failure, which are consequences of various postoperative RV sequelae. ${ }^{2}$ Pulmonary regurgitation (PR), amplified by various degrees of residual pulmonary artery branches stenosis, ${ }^{6}$ may create chronic overload leading to RV function impairment. ${ }^{7}$ Moreover, $\mathrm{RV}$ dilation often observed in these patients is linked to 


$$
\begin{aligned}
& \text { Abbreviations and Acronyms } \\
& \begin{aligned}
\text { AP } & =\text { action potential } \\
\text { PR } & =\text { pulmonary regurgitation } \\
\text { PV } & =\text { pressure-volume } \\
\text { RV } & =\text { right ventricular } \\
\text { TOF } & =\text { tetralogy of Fallot }
\end{aligned}
\end{aligned}
$$

a QRS prolongation predicting malignant ventricular arrhythmia and sudden death. ${ }^{8}$ Pulmonary valve replacement may prevent $\mathrm{RV}$ failure, but the best timing for intervention is still not well defined. ${ }^{9}$

The aim of this study was to establish an easily reproducible porcine model of repaired TOF mimicking the effects of chronic RV overload. Hemodynamic, echocardiographic, and electrocardiographic parameters were analyzed at 2 steps of $\mathrm{RV}$ overload to follow the development of the disease. $\mathrm{RV}$ tissue remodeling was assessed by cellular electrophysiologic and histologic techniques at the end of follow-up.

\section{MATERIALS AND METHODS Experimental Design}

Eleven Landrace male piglets, 47 to 87 days old (weight $15-25 \mathrm{~kg}$ ), were studied in accordance with the Guide for the Care and Use of Laboratory Animals (National Institutes of Health, publication 85-23, revised in 1996). General anesthesia was performed with propofol $1 \%$, allowing endotracheal intubation, and maintained with isoflurane in $100 \%$ oxygen (Servo 900, Siemens-Elema AB, Solna, Sweden). Body length was measured from the wither to the root of the tail. Body surface area and biological length (square root of body surface area) were calculated. Peripheral oxygen saturation and heart rate were monitored noninvasively throughout the procedure.

Enlargement of the RV outflow tract was performed via a left thoracotomy. A side-biting vascular clamp was longitudinally placed across the pulmonary valve annulus without obstruction of the RV outflow tract. A pulmonary valve leaflet was excised, and the pulmonary infundibulum, annulus, and trunk were enlarged by a $2-\mathrm{cm}$-long elliptically shaped polytetrafluorethylene patch to ensure loss of valve integrity. Pulmonary artery banding, made of umbilical tape, was placed around the artery and secured for a final diameter of approximately $1 \mathrm{~cm}$ (Figure E1).

Animals were studied at 3 experimental steps: baseline and 3 and 4 months of follow-up. Six animals were operated (operated group), and 5 age-matched animals were used as controls (control group). At each experimental step, animals underwent electrocardiography, echocardiography, and cardiac catheterization. In the operated group, baseline parameters were recorded before surgery. Cellular electrophysiologic and histologic studies were conducted after sacrifice at 4 months of follow-up.

\section{Echocardiography}

Transthoracic echocardiography was performed with a Hewlett-Packard Sono 1500 echograph (Andover, Mass). The tricuspid/mitral diameters ratio was calculated from tricuspid and mitral annulus diameters measured at the maximal valve opening during diastole. The pulmonary annulus was measured at the maximal pulmonary valve opening during systole. The presence of pulmonary stenosis or regurgitation was visualized using color Doppler flow. Transpulmonary gradient through the pulmonary band was evaluated by continued Doppler flow.

\section{Hemodynamic Study}

Contractile performance of the RV was assessed by the conductance catheter technique. ${ }^{10}$ Cardiac catheterization was performed through artery and vein introducers placed through a cut-down. The reference cardiac output was measured by using the transpulmonary thermodilution technique (PiCCO system, Pulsion Medical Systems, Munich, Germany) to obtain a systemic cardiac output reflecting the efficient pulmonary output independently of the effect of PR; the mean of 3 consecutive recordings was reported. After pressure calibration, a combined conductance-pressure catheter (CD Leycom, Zoetermeer, The Netherlands) was inserted into the $\mathrm{RV}$ apex and connected to a signal conditioner processor (Leycom Sigma-5, CardioDynamics, Leyden, The Netherlands) to acquire an instantaneous RV volume signal processed on dedicated software (Conduct NT; CD Leycom, Zoetermeer, The Netherlands). All recordings were corrected in accordance with measured blood resistivity. ${ }^{10}$ Parallel conductance was determined by the hypertonic $5 \%$ saline technique. Ventilation was arrested during data collection. At least 10 pressure-volume (PV) loops were acquired during cardiac output measurements with the PiCCO system to calibrate the stroke volume. The PV loops were recorded during 10 seconds of apnea without intervention, and the basal state was assessed 5 minutes before occlusion maneuver. The PR fraction was measured from the PV loops as the ratio between the PR volume and the total RV stroke volume. ${ }^{11}$ The efficient stroke volume was calculated as the difference between the total stroke volume and the measured volume of PR. The efficient ejection fraction was calculated as the ratio between efficient stroke volume and end-diastolic volume. A balloon-tipped catheter (Tyshak $20 \mathrm{~mm}$; NuMed Inc, Hopkinton, NY) was inserted through the jugular vein, and its tip was situated just inferior to the right atrium for the purpose of abrupt alteration of $\mathrm{RV}$ preload by vena cava occlusion. Series of PV loops were obtained for each animal during the vena cava occlusion. The end-systolic PV relationship describing the ventricular contractile status was examined during the vena cava occlusion, and the slope of end-systolic PV relationship $\left(\mathrm{E}_{\max }\right)$ was computed. ${ }^{10}$

\section{Electrocardiography}

A 12-lead surface electrocardiogram was recorded and digitized by a Philips PageWriter Trim II cardiograph (Philips Medical Systems, Eindhoven, The Netherlands). QRS duration was electronically measured on a $500-\mathrm{Hz}$ sample and defined as the maximal QRS length in any lead from the first inflection to the final sharp vector crossing the isoelectric line.

\section{Cellular Electrophysiologic Study}

Hearts were rapidly removed, and right ventricles were perfused by the right coronary artery for 15 minutes with a modified cold Tyrode solution containing (in millimoles per liter) $0.45 \mathrm{CaCl}_{2}, 2,3$ butanedione monoxine, and heparin $1250 \mathrm{UI} / \mathrm{L}$. Right endocardial ventricular trabeculae were dissected and bathed with Tyrode solution at $35{ }^{\circ} \mathrm{C}$ containing (in millimoles per liter) $120 \mathrm{NaCl}, 5.6 \mathrm{KCl}, 0.6 \mathrm{PO}_{4} \mathrm{H}_{2} \mathrm{Na}, 24 \mathrm{CO}_{3} \mathrm{HNa}, 1.1 \mathrm{MgCl}_{2}, 1.8$ $\mathrm{CaCl}_{2}, 10$ glucose, $1.8 \mathrm{Na}$ pyruvate, and 0.2 polyvinylpyrrolidone, and gassed with $5 \% \mathrm{CO}_{2}$ and $95 \% \mathrm{O}_{2}(\mathrm{pH} 7.4)$. Preparations were stimulated at $1 \mathrm{~Hz}$ (pulse duration, 2-3 ms) and allowed to recover for 1 hour before action potential (AP) recording by intracellular $3 \mathrm{M} \mathrm{KCl}$ microelectrodes (15-30 $\mathrm{M} \Omega$ ). Resting membrane potential, AP amplitude, AP duration at $50 \%$ and $90 \%$ of repolarization, and maximum upstroke velocity of the $\mathrm{AP}$ and AP area were determined at 4 months in both operated and control groups.

\section{Histologic Study}

Tissue samples were collected after RV perfusion on the equatorial plane fixed in $4 \%$ formalin and embedded in paraffin. Sections ( $3 \mu \mathrm{m}$ thick) were stained with Picrosirius red F3BA, Masson's trichrome, orcein, hematoxylin-eosin, or periodic-acid Schiff. Slides were examined at $20 \times$ magnification, fields were recorded with an AxioCam MRc camera (Carl Zeiss, 
Oberkochen, Germany), and analyses were conducted by 2 independent investigators. The interstitial collagen quantification was performed after Picrosirius red coloration on 3 sections (10 fields/section) per animal and expressed as a percentage of the total tissue. ${ }^{12}$ The myocyte diameter was determined after Masson's trichrome coloration by measuring the short axis of 30 randomly chosen cells per field ( 30 fields per animal), and the amount of myolysis was considered as severe if more than $25 \%$ of the sarcomere was absent.

\section{Statistical Analysis}

Data were expressed as mean values \pm standard error of the mean. For cellular electrophysiology and histology, average values for each parameter in each animal were calculated. Groups were compared by 1-way analysis of variance for repeated measurements, including post hoc analysis.

\section{RESULTS}

\section{Clinical Characteristics}

During the post-surgery and post-catheterization periods, all animals gained weight and showed no clinical signs of heart failure. Delays after operation were $92 \pm 3$ days at 3 months and $137 \pm 4$ days at 4 months. Similar delays were observed for the control group, $99 \pm 4$ days at 3 months and $133 \pm 4$ days at 4 months. Populations were similar in each group at each step in terms of age, weight, body surface area, and biological length; heart rates decreased in time but were similar for both groups (Table 1).

\section{Echocardiographic and Hemodynamic Data}

On echocardiography, operated animals showed a marked stenosis through the pulmonary banding: Maximal and mean gradients through the pulmonary band were significantly elevated at 3 months without any change at 4 months (Table 1). In these animals, an important $P R$ was detected by color Doppler at 3 and 4 months, secondary to the significant enlargement of pulmonary annulus diameter. The operated group showed clear signs of a pronounced RV dilation, as shown by the significant increase of tricuspid/mitral annulus ratios at 3 months, persisting at the same level at 4 months (Table 1). Conversely, the control group showed normal echocardiographic parameters during the follow-up.

Quantification of barometric and volumetric overload degree was performed by measuring intracardiac pressures (Table 1) and RV volumes (Figure 1). The central venous pressure was normal in both groups at each step. In the operated group, RV end-systolic pressure increased significantly at 3 months, remaining stable at 4 months; peak pressure significantly increased to a level of $75 \%$ of systemic pressure at 4 months; RV end-diastolic pressure progressed and was significantly higher than in the control group at 3 and 4 months. The PR fraction was similar at baseline in control and operated groups, $6.4 \% \pm 4.5 \%$ and $5.6 \% \pm 3.4 \%$, respectively; the PR fraction increased progressively in the operated group and was significantly higher than in the control group at 3 and 4 months (22.3\% $\pm 1.9 \%$ vs $4.6 \% \pm 1.9 \%$, respectively, $P<.05$ and
$25.0 \% \pm 4.7 \%$ vs $3.0 \% \pm 1.8 \%$, respectively, $P<.05$ ). End-systolic and end-diastolic volumes were markedly increased in the operated group at 3 months and significantly higher than in the control group at 4 months (Figure 1, A, $B$ ), whereas efficient stroke volume progressed as in the control group (Figure 1,C). These results indicate a combined barometric and volumetric RV overload consistent with echocardiographic parameters.

In the operated group, the cardiac index was stable (Figure $1, D$ ) and the efficient ejection fraction was significantly decreased at 4 months (Figure 1,E), whereas the stroke work clearly progressed at each step and was significantly higher than in the control group at 4 months (Figure 1,F). Moreover, in the operated group, myocardial contractility assessed by $E_{\max }$ showed a significantly elevated $E_{\max }$ at 3 months compared with baseline and the control group, suggesting a positive change in inotropism. A significant rightward shift of $E_{\max }$ slope returning to the baseline value was observed 4 months after surgery (Figure 2). No significant variation of $E_{\max }$ was observed in the control group at the different steps of follow-up.

\section{QRS Duration and Cellular Electrical Properties of the Right Ventricle}

The mean QRS duration at baseline was similar in the operated and control groups ( $58 \pm 3 \mathrm{~ms}$ and $61 \pm 3 \mathrm{~ms}$, respectively). The control group showed no significant variation in QRS duration during the follow-up ( $68 \pm 5 \mathrm{~ms}$ and $72 \pm 6$ $\mathrm{ms}$ at 3 and 4 months, respectively). In the operated group, a significant prolongation of the mean QRS duration was observed at 3 months ( $77 \pm 5 \mathrm{~ms}, P<.05$ vs baseline) and was slightly more at 4 months $(81 \pm 4 \mathrm{~ms}, P<.05$ vs baseline). The evolution of QRS duration between the 2 groups with time was significantly different.

At the cellular level, after 4 months of RV overload, AP amplitudes, AP durations at $90 \%$ of repolarization, and $\mathrm{AP}$ areas were significantly increased in the operated group, whereas no differences in resting membrane potential and maximum upstroke velocity of AP were observed (Table 2).

\section{Right Ventricular Tissue Remodeling}

Four months after surgery, a collagen accumulation was detected in interstitial spaces and between fiber bundles $(20.7 \% \pm 10.3 \%$ vs $13.4 \% \pm 5.5 \%$ in control group, $P<.001)$, whereas the control group showed narrow myocytes, well-aligned and surrounded by thin interstitial tissues (Figure 3, $A, B$ ). No elastic fibers were identified between myocytes in both groups (Figure 3, $C, D$ ). In the operated group, myocytes were significantly enlarged $(18.3 \pm 4.4$ $\mu \mathrm{m}$ vs $14.3 \pm 2.9 \mu \mathrm{m}$ in the control group, $P<.001)$, whereas no intracellular myolysis was observed (Figure 3, $E, F)$. No inflammation and glycogen granules were detected (data not shown), suggesting a partial remodeling of the RV tissue. 
TABLE 1. Population characteristics, echocardiography data, and intracardiac pressures in control and operated groups at each step of experimentation

\begin{tabular}{|c|c|c|c|c|c|c|}
\hline \multirow[b]{3}{*}{ Group } & \multirow{2}{*}{\multicolumn{2}{|c|}{ Baseline }} & \multicolumn{4}{|c|}{ Follow-up } \\
\hline & & & \multicolumn{2}{|c|}{ At 3 months } & \multicolumn{2}{|c|}{ At 4 months } \\
\hline & $\begin{array}{c}\text { Control } \\
n=5\end{array}$ & $\begin{array}{c}\text { Operated } \\
n=6\end{array}$ & $\begin{array}{c}\text { Control } \\
\mathbf{n}=5\end{array}$ & $\begin{array}{c}\text { Operated } \\
n=6\end{array}$ & $\begin{array}{c}\text { Control } \\
n=5\end{array}$ & $\begin{array}{c}\text { Operated } \\
n=6\end{array}$ \\
\hline \multicolumn{7}{|l|}{ Population characteristics } \\
\hline Age (d) & $64.4 \pm 7.3$ & $71.5 \pm 1.2$ & $162.0 \pm 7.7^{*}$ & $163.8 \pm 3.7 *$ & $193.6 \pm 6.8^{*} \ddagger$ & $206.8 \pm 3.2^{* \cdot \dagger}$ \\
\hline Weight (kg) & $18.3 \pm 1.9$ & $18.9 \pm 1.1$ & $41.4 \pm 4.2^{*}$ & $45.2 \pm 4.2^{*}$ & $47.1 \pm 4.4^{*} \dagger$ & $56.8 \pm 3.0 * \dagger$ \\
\hline Body length (cm) & $61.6 \pm 2.8$ & $64.5 \pm 1.3$ & $80.4 \pm 2.2^{*}$ & $84.8 \pm 3.0^{*}$ & $84.4 \pm 3.1^{*} \ddagger$ & $91.3 \pm 1.8^{* \dagger}$ \\
\hline Body surface area $\left(\mathrm{m}^{2}\right)$ & $0.56 \pm 0.04$ & $0.58 \pm 0.02$ & $0.96 \pm 0.06^{*}$ & $1.03 \pm 0.07 *$ & $1.05 \pm 0.07^{*} \ddagger$ & $1.20 \pm 0.04^{*} \ddagger$ \\
\hline Biological length (m) & $0.74 \pm 0.03$ & $0.76 \pm 0.01$ & $0.98 \pm 0.03^{*}$ & $1.01 \pm 0.04 *$ & $1.02 \pm 0.03^{*} \ddagger$ & $1.10 \pm 0.02^{*, \dagger}$ \\
\hline Heart rate (beats/min) & $122 \pm 11$ & $135 \pm 8$ & $102 \pm 7^{*}$ & $106 \pm 6^{*}$ & $97 \pm 12^{*} \ddagger$ & $90 \pm 4^{*} \ddagger$ \\
\hline \multicolumn{7}{|l|}{ Echocardiographic data } \\
\hline Ratio $\mathrm{T} / \mathrm{M}$ diameters & $0.80 \pm 0.05$ & $0.75 \pm 0.03$ & $0.84 \pm 0.03$ & $1.16 \pm 0.06^{*} \dagger$ & $0.77 \pm 0.04$ & $1.20 \pm 0.05^{*, \dagger}$ \\
\hline $\mathrm{PA}$ annulus diameter/L (mm) & $16.9 \pm 0.8$ & $16.8 \pm 0.4$ & $17.4 \pm 0.7$ & $21.3 \pm 1.3^{*} \dagger$ & $16.2 \pm 0.9$ & $21.3 \pm 0.9^{*} \uparrow$ \\
\hline $\mathrm{RV} / \mathrm{PA}$ maximal gradient $(\mathrm{mm} \mathrm{Hg})$ & $2.0 \pm 0.4$ & $2.4 \pm 0.2$ & $2.5 \pm 0.4$ & $44.7 \pm 9.5^{*} \dagger$ & $2.2 \pm 0.3$ & $45.6 \pm 11.7^{*} \uparrow$ \\
\hline $\mathrm{RV} / \mathrm{PA}$ mean gradient $(\mathrm{mm} \mathrm{Hg})$ & - & - & $1.4 \pm 0.2$ & $28.9 \pm 6.2 \dagger$ & $1.2 \pm 0.2$ & $30.1 \pm 8.2 \dagger$ \\
\hline \multicolumn{7}{|l|}{ Intracardiac pressures } \\
\hline Mean aortic blood pressure $(\mathrm{mm} \mathrm{Hg})$ & $70.0 \pm 5.1$ & $65.8 \pm 7.4$ & $74.4 \pm 6.7$ & $76.5 \pm 4.7$ & $69.8 \pm 4.3$ & $62.7 \pm 4.9$ \\
\hline Systolic aortic blood pressure (mm Hg) & $86.0 \pm 5.4$ & $83.7 \pm 8.5$ & $91.0 \pm 6.6$ & $97.7 \pm 3.9$ & $86.8 \pm 4.3$ & $84.5 \pm 4.9$ \\
\hline Central venous pressure (mm $\mathrm{Hg}$ ) & $1.8 \pm 0.6$ & $2.7 \pm 1.1$ & $1.6 \pm 0.7$ & $3.8 \pm 1.1$ & $2.2 \pm 0.5$ & $4.0 \pm 1.4$ \\
\hline \multicolumn{7}{|l|}{$\mathrm{RV}$ pressure $(\mathrm{mm} \mathrm{Hg})$} \\
\hline Peak & $20.4 \pm 1.2$ & $16.8 \pm 1.2$ & $15.8 \pm 0.8$ & $63.8 \pm 11.4^{*} \dagger$ & $16.4 \pm 0.9$ & $63.7 \pm 10.7^{*} \dagger$ \\
\hline End systolic & $12.6 \pm 1.0$ & $11.5 \pm 0.8$ & $7.4 \pm 0.7$ & $54.8 \pm 10.6^{*} \dagger$ & $8.0 \pm 1.6$ & $53.8 \pm 10.1^{*} \dagger \dagger$ \\
\hline End diastolic & $1.6 \pm 0.6$ & $1.7 \pm 1.1$ & $-1.4 \pm 1.4$ & $6.0 \pm 1.2^{*} \dagger$ & $-1.4 \pm 0.7$ & $5.8 \pm 1.7^{*} \uparrow \dagger$ \\
\hline Ratio systolic pressure RV/aorta (\%) & $24 \pm 2$ & $21 \pm 2$ & $18 \pm 2$ & $68 \pm 14^{*} \dagger$ & $19 \pm 1$ & $76 \pm 12^{*} \dagger$ \\
\hline
\end{tabular}

$L$, Biological length (square root of body surface area); $M$, mitral; $P A$, pulmonary artery; $R V$, right ventricle; $T$, tricuspid. $* P<.05$ versus corresponding group at baseline. $\dagger P<.05$

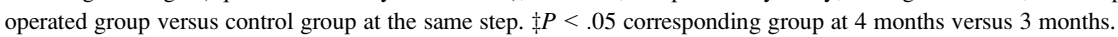

\section{DISCUSSION}

We have characterized an experimental model of chronic RV PV overload, as observed in congenital heart diseases, leading to the first stage of RV remodeling and applicable for therapeutic innovation.

Our study is the first to describe the various aspects of RV function in a large animal model, including hemodynamic, electrical, and histologic anomalies, in the presence of chronic PV overload. Among congenital heart diseases resulting in RV failure in the long term, TOF is the most frequent. The surgical technique, mimicking repaired TOF, is easily performed by experienced cardiac congenital surgeons and reproduces anomalies that are clinically observed at long term, including RV dilatation, QRS prolongation, $\mathrm{RV}$ function impairment, and structural changes. This model allows innovative therapeutic tests and determination of the best timing of intervention to treat RV tract diseases. ${ }^{9}$ Other studies conducted on experimental models of RV chronic overload mainly analyzed the hemodynamic effects on RV function ${ }^{13-15}$ and demonstrated a myocardial adaptation within an overload period of no more than 3 months. ${ }^{14,15}$ Thus, a longer period of observation seemed necessary to detect the RV remodeling and the first stage of dysfunction. In our study, the follow-up was more than 3 months, and final
$\mathrm{RV}$ functional and structural analyses were performed 4 months after surgery.

This experimental model was created using the surgical procedure described by Zelster and colleagues. ${ }^{13}$ Our model showed a significant enlargement of the pulmonary annulus area and a marked PR. A pulmonary artery band added to create a mild pulmonary stenosis elevated RV peak pressures up to $75 \%$ of systemic pressure at the end of followup, as observed in patients with the most severe sequelae. This pulmonary banding, simulating the pulmonary branch stenosis observed in some patients after TOF repair, was performed downstream to the infundibulo-ventricular patch to amplify the PR as described by Chaturvedi and collaborators. ${ }^{6}$ One consequence of PR is a marked volumetric overload, despite the large variability of both end-systolic and end-diastolic volumes observed between each animal in the 2 groups. This inter-animal variability of volumes measured with a catheter-conductance technique was also observed in another porcine model, indicating a possible relation to the complex geometry of the RV chamber. ${ }^{10}$ The combined PV RV overload, secondary to this combination of pulmonary stenosis and regurgitation, tends to accelerate the RV dysfunction, as observed in both experimental and clinical situations. ${ }^{13,16}$ 

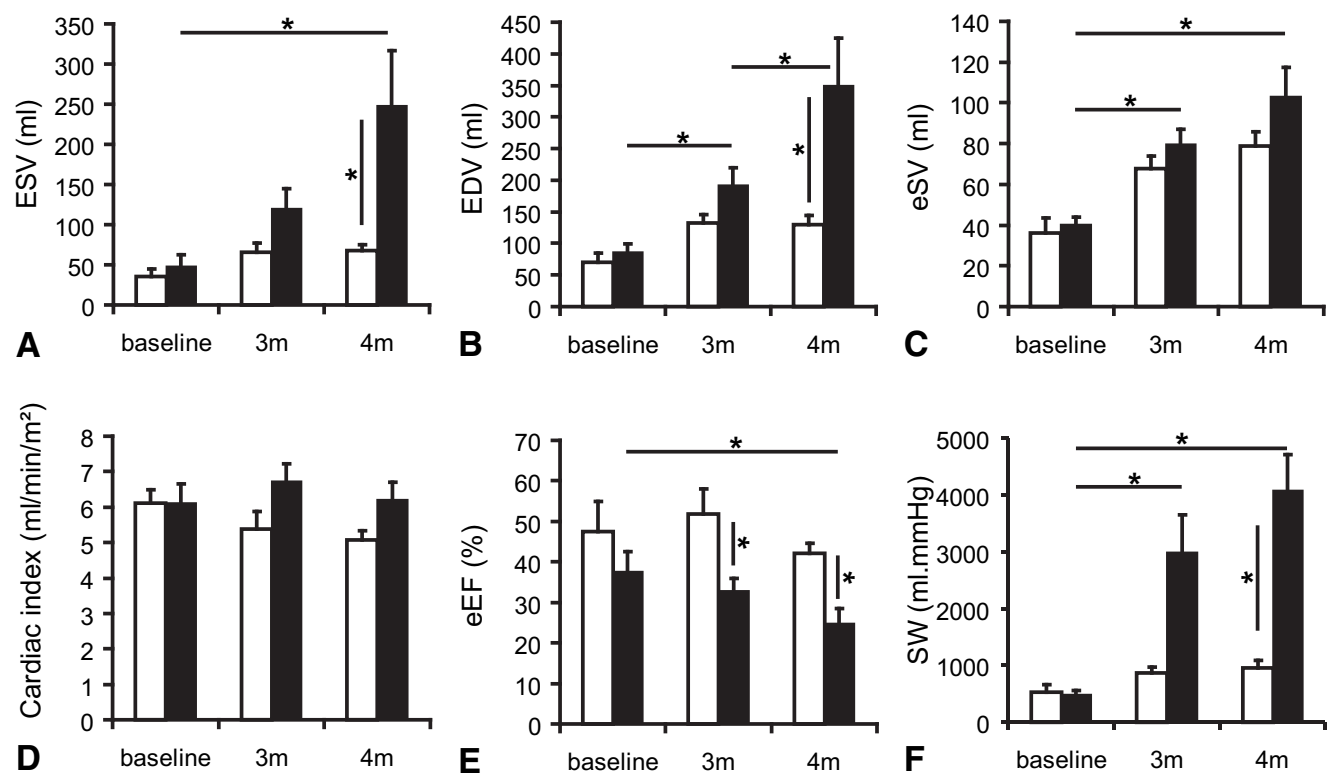

FIGURE 1. Hemodynamic parameters issued from PV loop measurements. Evolution of RV volumes (upper): end-systolic volume (A), end-diastolic volume (B), efficient stroke volume (C). Incidence of RV chronic overload on (lower) cardiac index (D), efficient ejection fraction (E), and stroke work (F). Values at baseline, 3 months, and 4 months in operated (black, $\mathrm{n}=6$ ) and control (white, $\mathrm{n}=5$ ) groups are plotted as mean \pm standard error of the mean. $* P<.05$.

The most important goal of this experimental model was to reproduce RV dysfunction. In regard to the RV myocardial contractility, $\mathrm{E}_{\max }$ changes differed according to the observation period in the operated group. At 3 months, $E_{\max }$ reached to the left and above the baseline, implying a positive inotropic change. This enhanced contractility corresponds with an increased RV contractility in the presence of acutely or chronically increased RV afterload described earlier. ${ }^{14,15}$ These studies suggested the RV homeometric autoregulation as an important adaptation to RV pressure overload. ${ }^{15} \mathrm{~A}$ challenge was to identify the turning point from compensated hypertrophy to RV failure. At 4 months, a significant rightward shift of $E_{\max }$ returning to the baseline value was observed. This negative change in inotropism may be interpreted as normalization after the adaptation period because of the homeometric regulation. Conversely, the change may be considered as the first step of RV remodeling toward dysfunction because the RV overload was maintained. In support of this hypothesis, Kuehne and colleagues ${ }^{17}$ found that RV myocardial reserve and contractility were impaired after 3 months of evolution in a model of isolated PR and that the systolic pump performance was decreased similarly as observed in PR associated with pulmonary stenosis. ${ }^{14,17}$ In accordance with these findings, the efficient ejection fraction decreased and the cardiac index failed to appropriately increase in the operated group, despite the elevation of volumes and incremental stroke work. This suggests that the adaptative response to pathologic loading conditions is not sufficient and that the homeometric effects of pressure overload are transitory.
The late contractility decrease was associated with structural changes: Cardiomyocyte diameters and fibrosis rate were significantly increased in the operated group. This remodeling, previously described in other experimental RV overloaded models, seems to result from regional overexpression of growth factors. ${ }^{18,19}$ Moreover, cellular hypertrophy was also found in both RV pressure- and volume-overloaded models, and in patients with repaired TOF. ${ }^{18,20}$ Conversely, fibrosis was observed only in the pressure-overloaded model, with a possible link between diminished anatomic coronary vascular reserve and connective tissue proliferation. ${ }^{18}$ In our model, it seems difficult to relate fibrosis to pulmonary stenosis rather than PR in analogy to the human pathology. Although histologic studies were not reported for a long time after TOF repair, magnetic resonance imaging, performed in adult patients with isolated severe PR and RV dilatation, detected fibrosis related to impaired ventricular dysfunction and clinical arrhythmia. ${ }^{21}$ Our histologic findings are in agreement with these results and confirm the link between structural changes and functional abnormalities. We can postulate that mechanisms inducing progressive fibrosis are associated with ventricular dilatation and hypertrophy resulting from PR or stenosis that leads to adverse RV remodeling. The absence of myolysis, glycogen granules, and elastic fibers corroborates with the hypothesis that the RV dysfunction has just begun, and the process may be reversible if residual $\mathrm{RV}$ tract anomalies are treated or therapies are applied. ${ }^{16}$

The RV myocardial contractility impairment and tissular remodeling are consistent with the cellular electrophysiology 

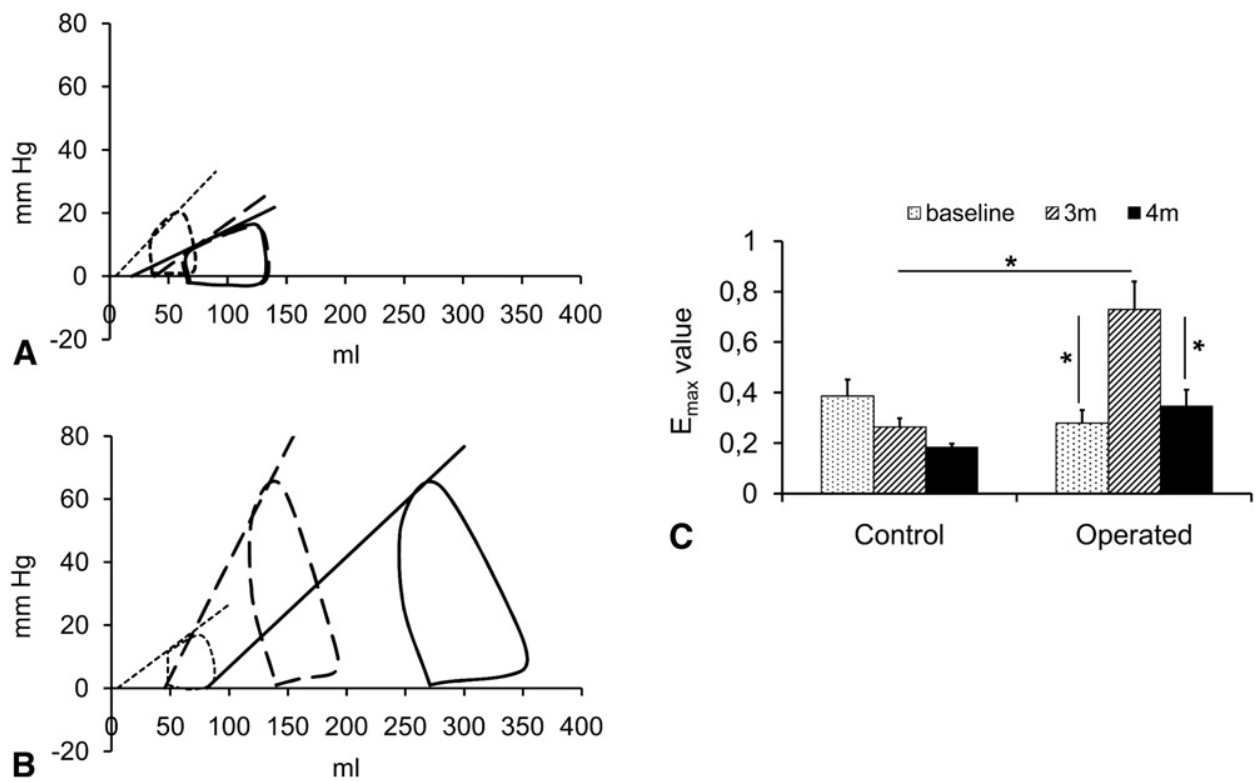

FIGURE 2. $\mathrm{E}_{\max }$ variation during follow-up: Representative PV loops and corresponding $\mathrm{E}_{\max }$ recorded in control (A) and operated (B) groups at baseline (dotted line), 3 months (dashed line), and 4 months (solid line). Note the marked increase of volume over time in the operated group. (C) $\mathrm{E}_{\max }$ mean values \pm standard error of the mean from 6 operated and 5 control animals at baseline (dotted), 3 months (hatched), and 4 months $($ black). $* P<.05$.

results showing an increase in repolarization parameters, especially action potential duration at $90 \%$ of repolarization. These modifications are usually encountered in hypertrophic and failed myocardia, ${ }^{22}$ and correspond to the repolarization dispersion found in patients late after TOF repair. ${ }^{23}$ In these patients, a depolarization in homogeneity conveyed by a QRS prolongation is also observed ${ }^{23}$ as the result of $\mathrm{RV}$ outflow tract abnormalities ${ }^{24}$ and diffuse RV myocardial anomalies. ${ }^{25}$ Prolongation of QRS is recognized as a major risk for severe ventricular arrhythmias and responsible for an increased risk of sudden death. ${ }^{8}$ Recent studies demonstrated a mechanoelectrical interaction and a direct relationship among QRS duration, RV size, and function in patients and an experimental model. ${ }^{8,13}$ This is consistent with the significant $\mathrm{QRS}$ prolongation found in our operated group. Because QRS prolongation is considered as a marker of prognosis strongly related to RV function, ${ }^{8}$ this parameter

TABLE 2. Right ventricular action potential parameters in control and operated groups

\begin{tabular}{lcc}
\hline \multicolumn{1}{c}{ Group } & $\begin{array}{c}\text { Control } \\
\mathbf{n = 3}\end{array}$ & $\begin{array}{c}\text { Operated } \\
\mathbf{n}=\mathbf{5}\end{array}$ \\
\hline Cell no. & 104 & 198 \\
MP $(\mathrm{mV})$ & $-76.4 \pm 0.7$ & $-76.2 \pm 0.5$ \\
AP amplitude $(\mathrm{mV})$ & $93.6 \pm 1.1$ & $98.2 \pm 0.7^{*}$ \\
Vmax $(\mathrm{V} / \mathrm{s})$ & $148.4 \pm 12.3$ & $128.2 \pm 8.8$ \\
APD $90 \%(\mathrm{~ms})$ & $260.5 \pm 3.1$ & $295.0 \pm 4.8^{*}$ \\
AP area $(\mathrm{mV} / \mathrm{ms})$ & $17,727 \pm 370$ & $21,599 \pm 413^{*}$ \\
\hline$M P$, Membrane potential; $A P$, action potential; Vmax , maximum upstroke velocity of \\
the AP ascending phase; $A P D$ 90\%, action potential duration at $90 \%$ of repolarization. \\
$* P<.05$.
\end{tabular}

may contribute to the evaluation of the RV remodeling in experimental therapeutic studies.

\section{CONCLUSIONS}

We have established and characterized an experimental porcine model of repaired TOF leading to RV dysfunction secondary to chronic combined PV overload that is applicable for therapeutic innovation and determination of the best timing of intervention. ${ }^{9}$ Moreover, in several other congenital heart diseases, the RV, being the dominant or systemic ventricle, sustains systemic overload and develops longterm dysfunction. Therefore, this model may contribute to the study of RV failure occurring in other types of congenital heart involving chronic RV PV overload. RV failure occurs in young adult patients a long time after TOF repair, ${ }^{2}$ but the impairment of overloaded RV contractility exists long before heart failure signs become evident. ${ }^{17}$ Our study describes RV remodeling diseases at an early stage and may help to identify a parameter in the timing of RV dysfunction evolution to test therapeutics that will prevent RV failure. Therapeutic studies may be initiated with innovating concepts such as cell therapy. The effects on the different aspects of RV failure, best timing of treatment, and optimal modalities of administration should be evaluated.

The authors thank Dr Jean Losay for revising the manuscript, Benoit Decante, Dr Bertrand Léobon, Dr François Roubertie, Dr Nawel Bensari, Bruno Baudet, Frédéric Seccatore, Maité Ghienne, and Karine Charles for excellent technical assistance, and the Farm of Bligny (France) for animal care. 

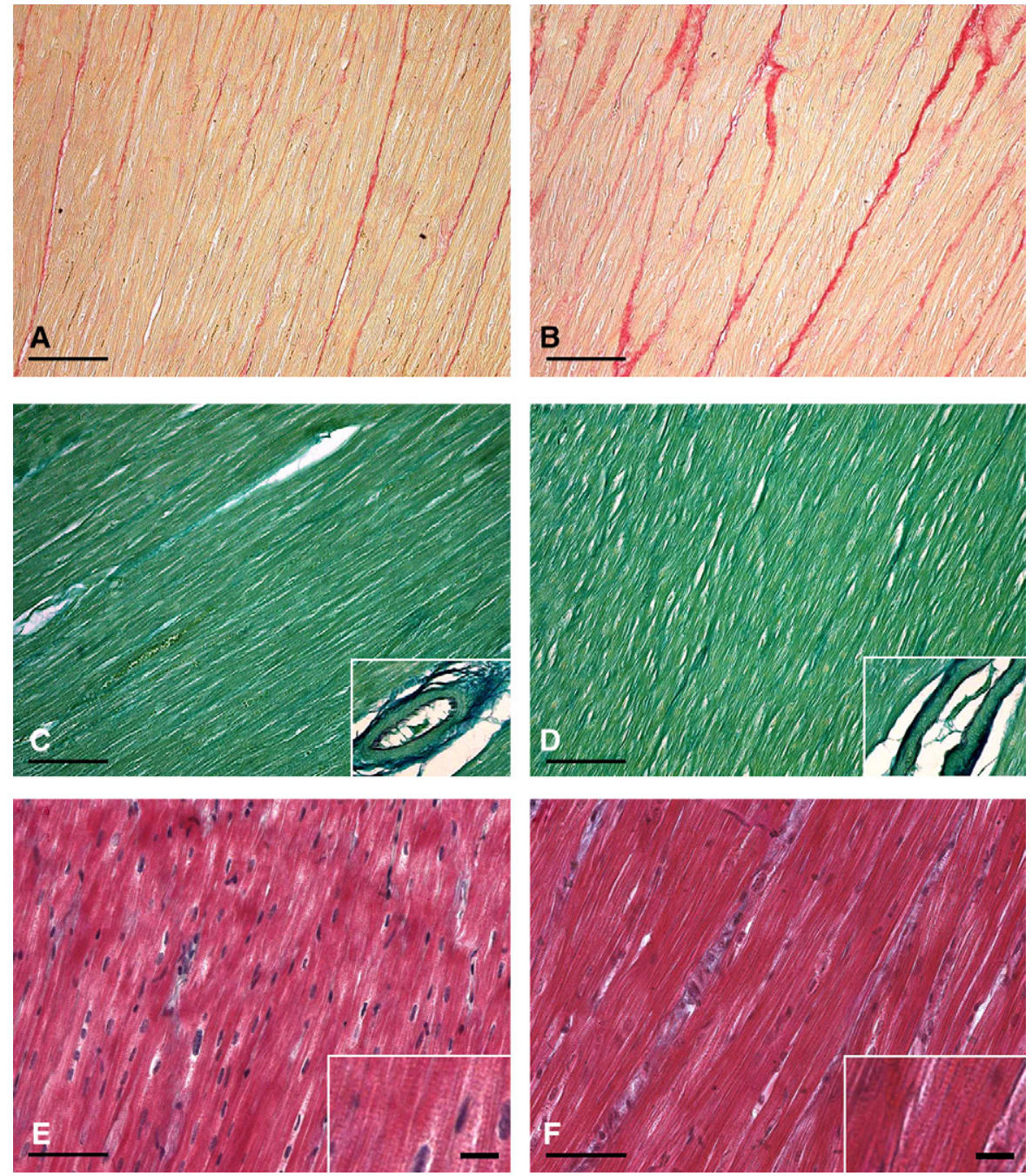

FIGURE 3. Tissue sections from control (A, C, E) and operated (B, D, F) animals after Picrosirius red (A, B), orcein (C, D), and Masson's trichrome (E, F) staining at 4 months. Bar $=50 \mu \mathrm{m}$. No elastic fibers were observed in both groups outside of vessels (inserts C, D). Higher magnification (inserts E, F) shows absence of myolysis but myocyte hypertrophy in operated animals. Bar $=20 \mu \mathrm{m}$.

\section{References}

1. Redington AN. Physiopathology of right ventricular failure. Semin Thorac Cardiovasc Surg Pediatr Card Surg Ann. 2006;9:3-1.

2. Nollert G, Fischlein T, Bouterwek S, Böhmer C, Klinner W, Reichart B. Longterm survival in patients with repair of tetralogy of Fallot: 36-year follow-up of 490 survivors of the first year after surgical repair. J Am Coll Cardiol. 1997;30: 1374-83.

3. Boucek MM, Waltz DA, Edwards LB, et al. Registry of the International society for heart and lung transplantation: Ninth official pediatric heart transplantation report 2006. J Heart Lung Transplant. 2006;25:893-903.

4. Dore A, Houde C, Chan KL, et al. Angiotensin receptor blockade and exercise capacity in adults with systemic right ventricles: a multicenter, randomized, placebo controlled clinical trial. Circulation. 2005;112:2411-6.

5. Mital S. Right ventricle in congenital heart disease: is it just a "weaker" left ventricle? Arch Mal Coeur Vaiss. 2006;99:1244-51.

6. Chaturvedi RR, Kilner PJ, White PA, Bishop A, Szwarc R, Redington AN. Increased airway pressure and simulated branch pulmonary artery stenosis increase pulmonary regurgitation after repair of tetralogy of Fallot. Circulation. 1997;95: 643-9.

7. Bove EL, Byrum CJ, Thomas FD, et al. The influence of pulmonary insufficiency on ventricular function following repair of tetralogy of Fallot. $J$ Thorac Cardiovasc Surg. 1983;85:691-6.
8. Gatzoulis MA, Till JA, Somerville J, Redington AN. Mechanoelectrical interaction in tetralogy of Fallot. QRS prolongation relates to right ventricular size and predicts malignant ventricular arrhythmias and sudden death. Circulation. 1995;92:231-7.

9. Geva T. Indications and timing of pulmonary valve replacement after tetralogy of Fallot. Semin Thorac Cardiovasc Surg Pediatr Card Surg Ann. 2006;9:11-22.

10. Dickstein ML, Yano O, Sponitz HM, Burkhoff D. Assessment of right ventricula contractile state with the conductance catheter technique in the pig. Cardiovasc Res. 1995;29:820-6.

11. Redington AN, Oldershaw PJ, Shinebourne EA, Rigby ML. A new technique for the assessment of pulmonary regurgitation and its application to the assessment of right ventricular function before and after repair of tetralogy of Fallot. Br Heart J. 1988;60:57-65.

12. Rucker-Martin C, Milliez P, Tan S, et al. Chronic hemodynamic overload of the atria is an important factor for gap junction remodeling in human and rat hearts. Cardiovasc Res. 2006;72:69-79.

13. Zelster I, Gaynor JW, Petko M, et al. The roles of chronic pressure and volume overload states in induction of arrhythmias: an animal model of physiologic sequelae after repair of tetralogy of Fallot. J Thorac Cardiovasc Surg. 2005;130: 1542-8.

14. Kuehne T, Gleason BK, Saeed M, et al. Combined stenosis and insufficiency preserves myocardial contractility in the developing heart of growing swine at midterm follow-up. J Appl Physiol. 2005;99:1422-7. 
15. De Vroomen M, Lopes Cardozo RH, Steendijk P, van Bel F, Baan J. Improved contractile performance of right ventricle in response to increased RV afterload in newborn lamb. Am J Physiol Heart Circ Physiol. 2000;278:H100-5.

16. Ilbawi M, Idriss F, DeLeon SY, et al. Factors that exaggerate the deleterious effects of pulmonary insufficiency on the right ventricle after tetralogy of Fallot repair: surgical implications. J Thorac Cardiovasc Surg. 1987;93:36-44.

17. Kuehne T, Saeed M, Gleason K, et al. Effects of pulmonary insufficiency on biventricular function in the developing heart of growing swine. Circulation. 2003; 108:2007-13.

18. Marino TA, Kent RL, Uboh CE, Fernandez E, Thompson EW, Cooper G. Structural analysis of pressure versus volume overload hypertrophy of cat right ventricle. Am J Physiol Heart Circ Physiol. 1985;249:H371-9.

19. Modesti P, Vanni S, Bertolozzi I, et al. Different growth factor activation in the right and left ventricles in experimental volume overload. Hypertension. 2004;43:101-8.

20. Mitsuno M, Nakano S, Shimazaki Y, et al. Fate of right ventricular hypertrophy in tetralogy of Fallot after corrective surgery. Am J Cardiol. 1993;72:694-8.
21. Babu-Narayan SV, Kilner PJ, Li W, et al. Ventricular fibrosis suggested by cardiovascular magnetic resonance in adults with repaired tetralogy of Fallot and its relationship to adverse markers of clinical outcome. Circulation. 2006;113: 405-13.

22. Doherty JD, Cobbe SM. Electrophysiological changes in animal model of chronic heart failure. Cardiovasc Res. 1990;24:309-16.

23. Gatzoulis MA, Till JA, Redington AN. Depolarization-repolarization inhomogeneity after repair of tetralogy of Fallot. The substrate for malignant ventricular tachycardia? Circulation. 1997;95:401-4.

24. Uebing A, Gibson DG, Babu-narayan SV, et al. Right ventricular mechanics and QRS duration in patients with repaired tetralogy of Fallot; implications of infundibulum disease. Circulation. 2007;116:1532-9.

25. Puranik R, Greaves K, Hawker RE, Pressley LA, Robinson PJ, Celermajer DS. Abnormal right ventricular tissue velocities after repair of congenital heart disease. Implications for late outcomes. Heart Lung Circ. 2007; $16: 295-9$. 

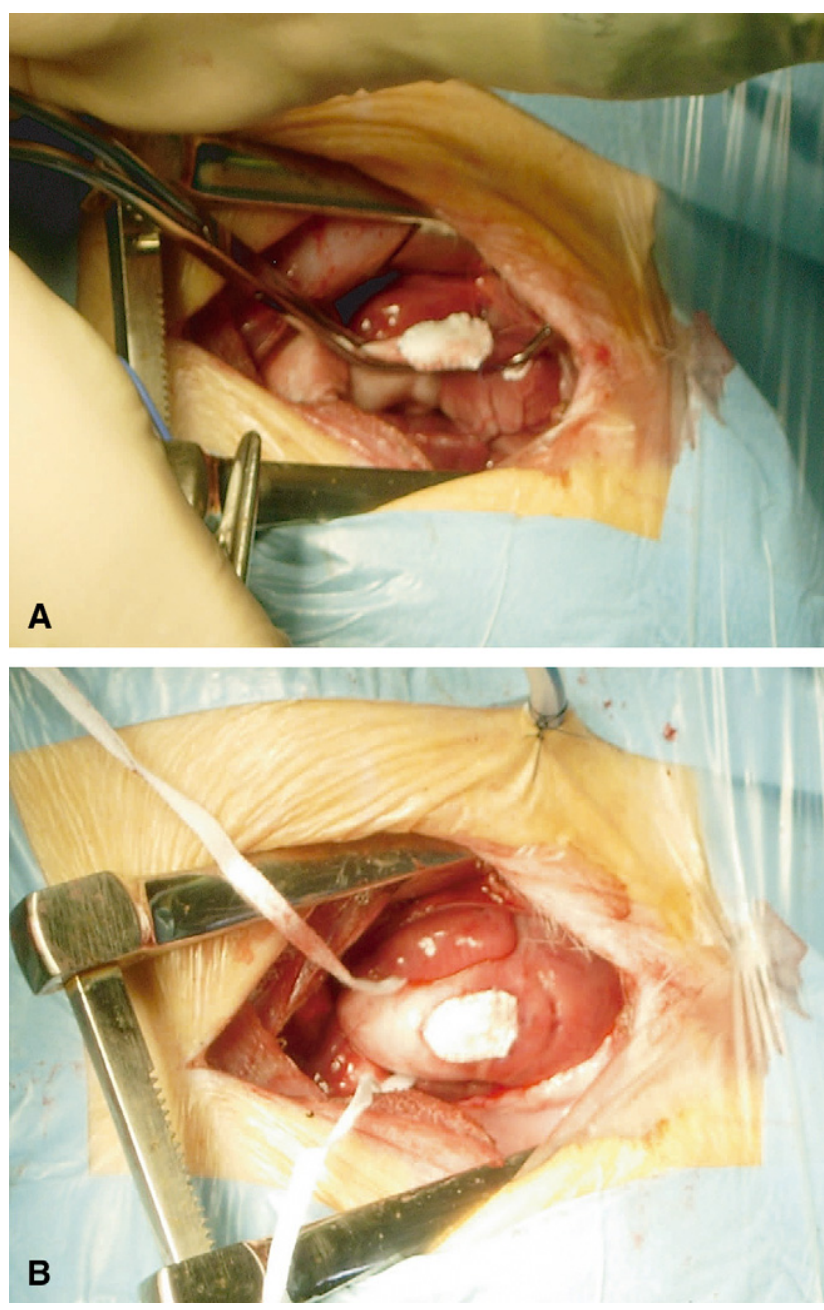

FIGURE E1. Two major steps of the surgical procedure: Enlargement of right ventricular (RV) outflow tract was performed via left thoracotomy. Sidebiting vascular clamp was longitudinally placed across the pulmonary valve annulus without obstruction of the RV outflow tract (A). Pulmonary valve leaflet was excised, and pulmonary infundibulum, annulus, and trunk were enlarged by a 2-cm-long elliptically shaped polytetrafluorethylene patch to ensure loss of valve integrity. Pulmonary artery banding, made of umbilical tape, was placed around the artery and secured for a final diameter of approximately $1 \mathrm{~cm}$ (B). 